\title{
Graphite/ $n$-InSe photosensitive junctions fabricated by transferring dry drawn graphite film onto as-cleaved surface of InSe
}

\author{
M.Z.Kovalyuk ${ }^{1}$, P.I.Savitskii ${ }^{1}$, M.V.Tovarnitskii ${ }^{1}$, O.S.Lytvyn ${ }^{2,3}$ \\ ${ }^{1}$ I.Frantsevich Institute for Problems of Materials Science, National Academy \\ of Sciences of Ukraine, 5 I.Vilde Str., 58001 Chernivtsi, Ukraine \\ ${ }^{2}$ V.Lashkaryov Institute of Semiconductor Physics, National Academy of \\ Sciences of Ukraine, 41 Prosp. Nauky, 03028 Kyiv, Ukraine \\ ${ }^{3}$ B.Grinchenko Kyiv University, 18/2 Bulvarno-Kudriavska Str., 04053 \\ Kyiv, Ukraine
}

Received March 3, 2020

\begin{abstract}
We report on reproducible fabrication and characterization of new photosensitive Schottky-type junctions prepared by an extremely simple technique when a substrate-free dry drawn graphite film is transferred from water surface onto as-cleaved van der Waals surface (0001) of $n$-InSe substrate. Electrical and photoelectric characterization of the obtained junctions is investigated using current-voltage, capacitance-voltage and photosensitivity spectra measurements. It is revealed that the thin graphite film transferred onto the $n$-InSe (0001) substrate creates a Schottky junction with a potential barrier of $0.49 \mathrm{eV}$ and rectification ratio of $R R \approx 200$ at $0.9 \mathrm{~V}$. An abrupt rectifying electrical junction graphite $/ n$-InSe is formed due to van der Waals attraction forces between the thin graphite film and atomically smooth $n$-InSe (0001) surface. The graphite $/ n$-InSe junctions generated short-circuit current density of $J_{s c}=0.29 \mathrm{~mA} / \mathrm{cm}^{2}$, open-circuit voltage of $V_{o c}$ $=0.31 \mathrm{~V}$ and filling factor of $F F=0.33$ under $80 \mathrm{~mW} / \mathrm{cm}^{2}$ white light illumination. The junctions exhibit photosensitivity in the near-infrared and visible spectral ranges, making them promising for photodetector applications. Their energy band diagram is built up.
\end{abstract}

Keywords: indium selenide, heterojunction, photosensitivity.

\footnotetext{
Фоточутливі переходи графіт/n-InSe, виготовлені шляхом перенесення сухонамальованої графітової плівки на свіжосколоту поверхню InSe. М.З.овалюк, П.І.Савицъкий, М.В.Товарницький, О.Сљитвин

Розглянуто відтворюване виготовлення та характеризація фоточутливих переходів типу Шотткі, сформованих надзвичайно простим методом, в якому графітова плівка, отримана шляхом сухого малювання, переноситься із водної поверхні на свіжосколоту поверхню (0001) підкладки $n$-InSe. Електричні та фотоелектричні характеристики отриманих переходів досліджено шляхом вимірювання вольт-амперних і вольт-фарадних характеристик та спектрів фоточутливості. Виявлено, що тонка графітова плівка, перенесена на поверхню (0001) підкладки $n$-InSe, утворює перехід Шотткі з потенціальним бар'єром 0,49 еВ і коефіцієнтом випрямлення $R R=200$ при 0,9 В. Різкий випрямляючий електричний перехід графіт $/ n$-InSe формується притягуючими ван-дер-ваальсівськими силами між тонкою графітовою плівкою і атомарно гладкою поверхнею (0001) $n$-InSe. Переходи графіт $/ n$-InSe генерують струм короткого замикання $J_{s c}=$ $0,29 \mathrm{~mA} / \mathrm{cm}^{2}$, напругу розімкнутого кола $V_{o c}=0,31 \mathrm{~B}$ та коефіцієнт заповнення $F F=$ 0,33 при освітленні білим світлом потужності $80 \mathrm{mBт} / \mathrm{cm}^{2}$. Переходи демонструють фоточутливість у ближній інфрачервоній та видимій областях спектра, що свідчить про можливість їх застосування як фотодетекторів. Побудовано енергетичну зонну діаграму таких переходів.
} 
Расмотрено воспроизводимое изготовление и характеризация фоточувствительных переходов типа Шоттки, изготовленных очень простым методом, при котором графитовая пленка, полученная путем сухого рисования, переносится из водной поверхности на свежесколотую поверхность (0001) подложки $n$-InSe. Электрические и фотоэлектрические характеристики полученных переходов исследованы путем измерения вольт-амперных и вольт-фарадных характеристик и спектров фоточувствительности. Обнаружено, что графитовая пленка, перенесенная на поверхность (0001) подложки $n$-InSe, образует барьер Шоттки с потенциальным барьером 0,49 эВ и коэффициентом випрямления $R R \approx 200$ при 0,9 В. Резкий выпрямляющий электрический переход графит $/ n$ InSe формируется притягивающими ван-дер-ваальсовскими силами между тонкой графитовой пленкой и атомарно гладкой поверхностью (0001) $n$-InSe. Переходы графит $/ n$ InSe генерируют ток короткого замыкания $J_{s c}=0,29 \mathrm{MA} / \mathrm{cm}^{2}$, напряжение разомкнутой цепи $V_{o c}=0,31 \mathrm{~B}$ и коэффициент заполнения $F F=0.33$ при освещении белым светом мощностью $80 \mathrm{mBт} / \mathrm{cm}^{2}$. Переходы обнаруживают фоточувствительность в ближней инфракрасной и видимой областях спектра, что указывает на возможность их применения как фотодетекторов. Построена энергетическая зонная диаграмма таких переходов.

\section{Introduction}

Future advances in the realm of graphene-like two-dimensional (2D) materials are associated with new van der Waals heterostructures [1]. The possibility of combining graphene with other layered 2D crystals in nanoscale structures offers new exciting opportunities for nanodevice fabrication, and the interest in the heterostructures fabricated by stacking various combinations of 2D crystals is growing exponentially [1]. The future success of the "van der Waals heterostructures" conception depends on understanding of the processes at graphene/layered semiconductor interface and fine control of charge transport through the junctions. Drawing with a graphite rod/pencil is the cheapest and simplest way of the solvent-free deposition of nanocomposite graphene-based films [2]. This approach is very attractive because of the great demand in the scalable production of large quantities of defect-free few-layer graphene.

Among exfoliable layered crystals suitable for van der Waals heterostructures, indium monoselenide (InSe), a direct-band gap III-VI semiconductor compound $\left(E_{g}=\right.$ $1.26 \mathrm{eV}$ at $T=300 \mathrm{~K}$ [3]), offers unique opportunities for applications in optoelectronics and nanoelectronics. The recent spark of interest in this material is associated with the observation of strong quantization effects in mechanically exfoliated nanosheets and the reported possibility of tuning the band gap in the near-infrared spectral range by reducing the flakes' thickness down to several nanometers [4]. These findings have already stimulated many new studies on InSe [5-8].

InSe layered crystals can be easily cleaved along the (0001) planes. Due to a low density of surface states [9], the (0001) surface (also called as "van der Waals surface") of InSe has been successfully utilized as a substrate for fabrication of high-quality photosensitive $p$ - $n$ junctions using a simple method of direct mechanical adhesion between thin films of layered crystals (also known as "optical contact method") [1012]. As-cleaved InSe (0001) surfaces are atomically smooth and do not require any additional treatment for electrical and optical applications [9]. To our knowledge, characterization of graphite/layered semiconductor junctions has not been reported earlier.

Various techniques have been applied for deposition of thin graphite films: chemical vapour deposition [13], cathodic plasma electrolysis [14], pulsed laser deposition [15], printing colloidal graphite [16], method based on van der Waals adherence of cleaved highly oriented pyrolytic graphite flakes [17] and even direct drawing graphite films onto semiconductor surface using a pure graphite rod [18]. However, our attention was attracted by a new, lowcost and technologically simple technique for fabrication of high quality graphite/semiconductor junctions using dry drawn graphite films, which was proposed in [19]. Here, we demonstrate that this technique can be applied for fabrication of photosensitive graphite/ $n$-InSe Shottky-type junctions with satisfactory reproducibility of electrical and photoelectrical parameters. It is reported on a detailed analysis of the electrical and photoelectric properties of the graphite $/ n$-InSe junctions prepared by transferring a dry drawn graphite film onto the van der Waals surface (0001) of $n$-InSe substrate.

It is known that a graphite rod can draw owing to the highly anisotropic layered structure of graphite. Graphite platelets are 
clearly seen when observing the surface of pencil drawn films by means of a scanning electron microscope [2]. It was demonstrated in $[20,21]$ that dry drawn graphite films cold be regarded as $2 \mathrm{D}$ nanostructures, as they are composed of randomly interacting multilayer graphene nanosheets and graphitic nanodomains. It was inferred in [17] that the barrier properties of graphite/semiconductor junctions were mainly determined by the first layer of graphite at the interface. The authors of [17] investigating various bulk graphite/semiconductor junctions have anticipated a similar phenomenon when substituting three-dimensional (3D) graphite for 2D graphene. Thus, our work may be regarded as a step towards understanding the interface nature of graphene $/ n$-InSe and further development of novel nanodevices.

\section{Experimental}

In this study we used undoped $n$-InSe single crystals grown by the Bridgman method from a non-stoichiometric melt $\ln _{1.03} \mathrm{Se}_{0.97}$. The grown crystals were studied by means of X-ray diffraction (XRD) measurements using a DRON-3 X-ray diffractometer in a monochromatic $\mathrm{Cu}-\mathrm{K}_{\alpha}$ radiation of wavelength $\lambda=$ $1.5418 \mathrm{E}$ and analyzed by means of LATTIK-KARTA software. The obtained XRD results revealed that the obtained crystals were rhombohedral $\gamma$ - InSe (R3m space group) with the lattice parameters $a=$ 4.002 and $c=24.961 \AA$. The room temperature Hall effect measurements showed that the InSe crystals were of $n$-type conductivity with the electron density in the range $10^{14}$ to $10^{15} \mathrm{~cm}^{-3}$. The electron mobility was determined to be $800-1000 \mathrm{~cm}^{2} / \mathrm{V} \cdot \mathrm{s}$.

Thin plates of InSe layered crystals were used as substrates in graphite/ $n$-InSe Shottky-type junctions. For their fabrication at ambient conditions we used a recently proposed technique described in [19]. According to this method, a homogeneous graphite layer was firstly drawn on a mechanically polished salt $(\mathrm{NaCl})$ substrate (typical dimensions of $4 \times 4 \times 1 \mathrm{~mm}^{3}$ ) using a pure graphite rod (pencil). Then the $\mathrm{NaCl}$ substrate was placed onto the surface of double distilled water. The graphite/NaCl structure was floating on the water surface during several minutes until the $\mathrm{NaCl}$ substrate became dissolved in the water. As a result, we obtained a substrate-free dry drawn thin graphite film on the water surface. The interaction forces between a large number of graphitic nanodomains and overlapped ul- trathin graphite sheets are strong enough to keep the film together. Then the obtained semitransparent thin graphite film was transferred onto the van der Waals surface (0001) of the $n$-InSe substrate. An abrupt graphite/nInSe junction is formed due to the adhesive van der Waals force between them.

To measure electrical and optical properties of the obtained graphite films, they were also transferred onto glass substrates. Using a four-probe method, we established that the room temperature sheet resistance of the graphite films was around $385 \Omega / \mathrm{sq}$. The optical transmittance was measured to be $\approx 21.2 \%$ at $550 \mathrm{~nm}$. The carried out micro-interferometry measurements revealed that the films were $180-200 \mathrm{~nm}$ thick. The front point contacts to the graphite films were fabricated using a conductive silver-based glue. High purity In was used as a back contact material providing good ohmic contact to $n$-type InSe. The active area $S$ of the junctions was $0.16 \mathrm{~cm}^{2}$.

The surface morphology of the samples was investigated by means of atomic force microscopy (AFM) using a Nanoscope IIIa Dimension 3000 SPM (Digital Instruments, USA). The AFM measurements were carried out in tapping mode in air after fabricating the samples.

The current-voltage $(J-V)$ and capacitance-voltage $(C-V)$ characteristics were measured by means of a Schlumberger SI 1255 \& 1286 amplitude-frequency analyzer at room temperature. The obtained results were analyzed using "ZView 3.0a" software. The photoelectric parameters of the junctions (open-circuit voltage $V_{o c}$ and short-circuit current density $J_{s c}$ ) under illumination were investigated to an accuracy of $0.5 \%$ using a standard stand.

The room temperature photosensitivity spectra were measured using a MDR-3 monochromator with a $26 \AA$ resolution. The illumination was directed onto the thin graphite film side. The spectral distribution of the relative quantum efficiency of photoconversion was determined as the ratio of photocurrent to number of incident photons.

\section{Results and discussion}

\subsection{Morphology characterization}

The morphology of the heterointerface between the semimetal graphite film and $n$-InSe semiconductor substrate is closely related to the properties of the graphite $/ n$-InSe junctions. Fig. 1 a,b,c shows AFM patterns of the surface morphology of the as-cleaved 


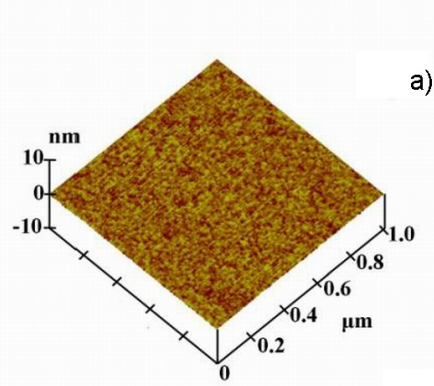

InSe(0001) surface

a)

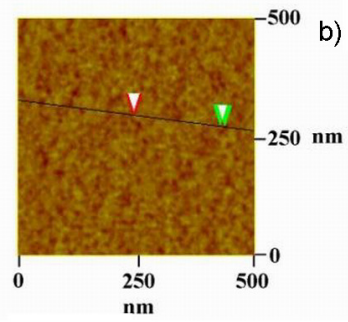

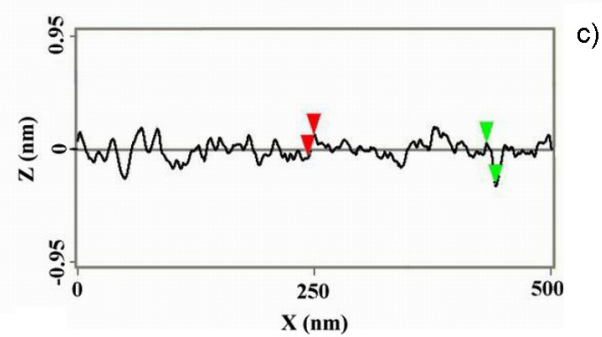

graphite/InSe(0001) surface

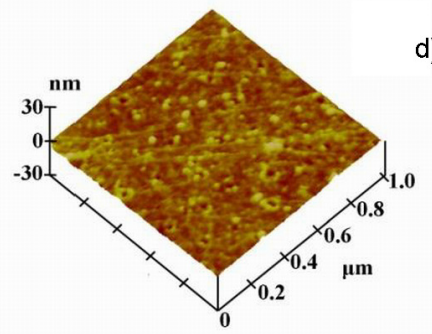

d)
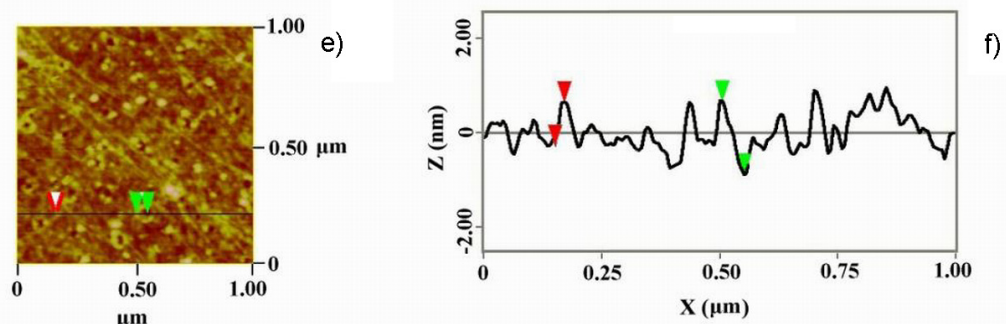

Fig. 1. Surface morphology of a freshly cleaved InSe (0001) surface (a and b) and the graphite film transferred onto this substrate ( $d$ and e): a and $d-3 D$ AFM images and $b$ and e - 2D AFM images; $c$ and $\mathrm{f}$ - cross-section profiles along the black lines shown in (b) and (e), respectively.

van der Waals surface (0001) of the InSecrystal used as a substrate and a thin dry drawn graphite film transferred from the water surface onto this substrate. The AFM patterns demonstrate that the surface (0001) of $n$-InSe substrate is almost atomically smooth with a root mean square (RMS) roughness of $\approx 0.08 \mathrm{~nm}$. One can see from Fig. 1,c that the maximum surface height deviation does not exceed $0.36 \mathrm{~nm}$. The obtained AFM results for the $n$-InSe (0001) surface are in good agreement with the literature [9, 32].

The surface morphology of the dry drawn graphite films was investigated after their transferring onto the $n$-InSe substrate (Fig. 1,d,e,f). It is clearly seen that the surface of the graphite/n-InSe structure is rougher than the as-cleaved surface (0001) of $n$-InSe. The AFM results revealed that the RMS roughness of this surface was equal to $\approx 0.39 \mathrm{~nm}$. The maximum surface height deviation did not exceed $1.54 \mathrm{~nm}$ (Fig. 1,f). The AFM measurements show that the surface of the graphite/n-InSe structure under investigation is relatively smooth with a low RMS roughness, which is very important for the fabrication technique used in this work, as for good mechanical adhesion between the thin graphite film and $n$-InSe substrate, the both contact- ing surfaces must be almost atomically smooth with minimal surface roughness.

\subsection{Electrical properties}

The room temperature $J-V$ characteristics of the graphite/n-InSe Schottkytype junctions (Fig. 2a) show a rectification with low leakage current densities at reverse bias. The junction is forward biased when a positive voltage is applied to the graphite film ( see the insert in Fig. 2a). The $J-V$ curves tend to slightly vary from sample to sample but all show strong rectification. The fact that the graphite $/ n$-InSe structures under investigation display well pronounced rectifying behaviour confirms the formation of a high-quality electrical junction between the thin graphite film and $n$-InSe substrate. The junctions show a rectification ratio $(R R)$, the ratio of forward current density $\left(J_{f o r}\right)$ to reverse current density $\left(J_{\text {rev }}\right)$, to be of about 200 at the applied voltage of $0.9 \mathrm{~V}$. The obtained value of $R R$ is higher or comparable with that reported for other rectifying InSe-based junctions [23, 24]. The experimental value of Schottky barrier height $\varphi_{b}=0.49 \mathrm{~V}$ was determined by extrapolating the linear part of the forward branch of the $J-V$ characteristic towards the intersection with the voltage axis (Fig. 2a). 

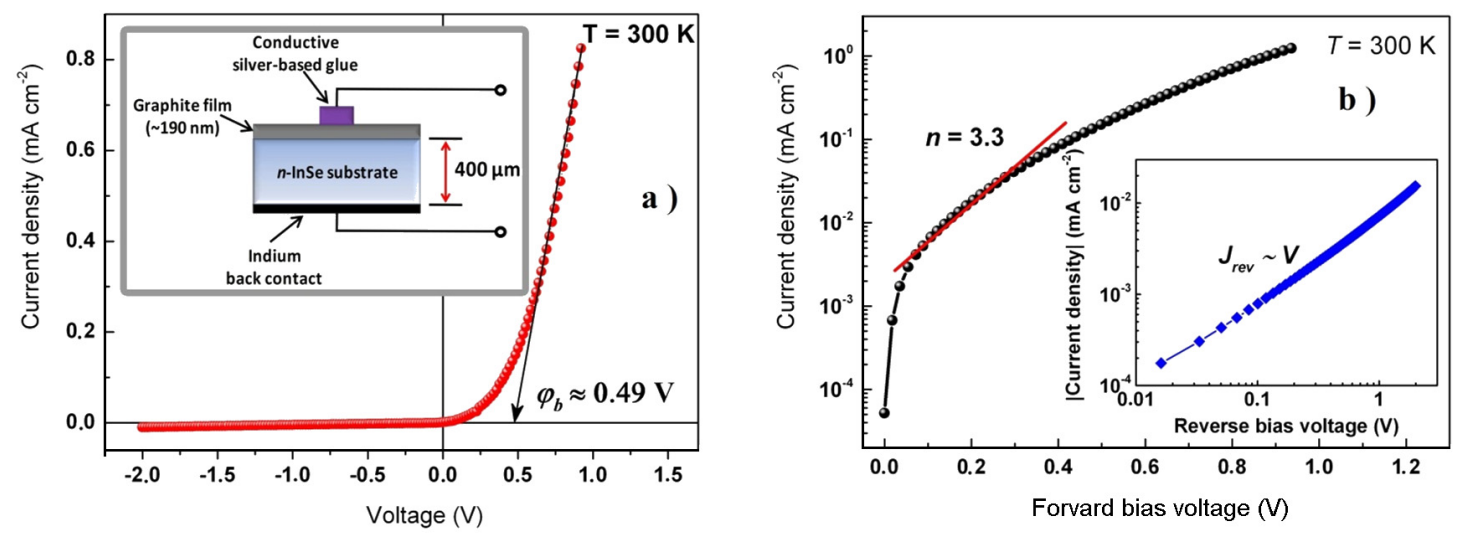

Fig. 2. a) The dark $J-V$ characteristic of the graphite/n-InSe junction. The inset shows a schematic illustration of the fabricated graphite $/ n$-InSe junction; b) the dark forward biased $J-V$ characteristic of the graphite $/ n$-InSe junctions. The straight red line corresponds to the $J=\exp \left[q /\left(V-J R_{s}\right) / n k T\right]$ dependence. The inset shows the dark reverse biased $J(V)$ characteristic in log-log scale.

From the additional measurements of impedance spectra and their modelling it is found that the series resistance $R_{s}$ of the junction is $3.5 \mathrm{k} \Omega$. This value is affected by the resistance of the quasi-neutral regions of the $n$-InSe substrate. For the Schottkytype junctions under investigation, its high value is caused by the low conductivity of $n$-InSe single crystals along the $c$-axis of hexagonal crystal, $\sigma_{\| c}$ (i.e across the layers) [25]. Therefore, the InSe-based structures have high resistance of the quasi-neutral regions. The values of $R_{s}$ of the same order of magnitude have been reported for various types of homo- and heterojunctions based on InSe layered crystals [23, 26].

Fig. $2 \mathrm{~b}$ shows the $J-V$ characteristics of the graphite/n-InSe junctions under forward and reverse biases plotted in semilogarithmic and log-log scales, respectively. The initial parts of the measured $J-V$ characteristic are governed by the following exponential dependence [27]:

$$
J=J_{s}\left[\exp \left(\frac{q V}{n k T}\right)-1\right],
$$

where $J$ is the current density, $J_{s}=$ $A^{*} T^{2} \exp \left(-q \varphi_{b} / k_{B} T\right)$ is the saturation reverse biased current density, $q \varphi_{b}$ is the zero bias Schottky barrier height, $A^{*}$ is the Richardson constant, $V$ is the applied voltage, $q$ is the elementary charge, $k$ is the Boltzmann's constant, $T$ is temperature and $n$ is the ideality factor. However, high values of the series resistance $R_{s}$ significantly complicate the analysis of the dark $J-V$ characteristics of $p-n$ and Schottky-type junctions. The series resistance largely affects the $J-V$ de- pendences because of the redistribution of the voltage drop between the potential barrier and the quasi-neutral regions of the investigated structure.

In order to take into account the value of the series resistance $R_{s}=3.5 \mathrm{k} \Omega$ defined from the impedance measurements, the experimental $J-V$ curve was replotted (Fig. 2b) using the equation

$$
J=J_{s}\left[\exp \left(\frac{q\left(V-J R_{s}\right)}{n k T}\right)-1\right] .
$$

It is clearly seen that the linear segment of the $J-V$ dependence corresponding to Eq. (2) becomes longer. The slope of the obtained curve (the straight red line in Fig. 2b) representing the linear segment of the $J-V$ dependence at a low forward bias $3 k T<V<0.4$ was used to calculate the ideality factor $n$ from the following equation [27]:

$$
n=\frac{q \Delta V}{k T \Delta \ln J}
$$

The value of $n$ was established to be equal to 3.3. This high value indicates on a deviation of the junction under investigation from an ideal Schottky barrier diode for which $n=1$. The significant deviation from the ideality points out the domination of recombination on defect-related interface states. The presence of defects at the interface invariably leads to an increase of the ideality factor. These defect-related interface states are inevitably formed during the fabrication of the graphite/ $n$-InSe junctions when the thin graphite films and $n$-InSe substrates are exposed to air and water at ambient conditions. Under such conditions, 
a thin intrinsic oxide layer may be formed on the substrate due to adsorption of oxygen, water or hydroxyl $\mathrm{OH}$-groups in the presence of defects in the chalcogen atomic planes [9, 28]. In addition, some interface defects can appear at mechanical cleaving the substrates. The presence of such uncontrolled defects affects the charge-carrier transport through the barrier.

At higher bias voltage $V>0.4 \mathrm{~V}$ the forward branch of the $J-V$ characteristic can be described by the linear dependence

$$
J=V-V_{0} R_{s}
$$

where $V_{0} \approx 0.49 \mathrm{~V}$ is the cut-off voltage determined from the forward $J-V$ characteristic in Fig. 2a. This deviation of the $J-$ $V$ dependence with the further increase of forward bias takes place due to the effect of the series resistance $R_{s}$. At high current density the $J-V$ characteristic reflects mainly the contribution of the voltage drop across the series resistance $R_{s}$, but not the real charge transport mechanisms through the potential barrier. One can see from the inset in Fig. 2b that the reverse $J-V$ dependence, when plotted in the $\lg \left(J_{\text {rev }}\right)$ vs. $\lg \left(V_{\text {rev }}\right)$ coordinates, within the reverse bias $0<|\mathrm{V}|<2$ represents a straight line with a slope $\approx 1$. It indicates that this dependence obeys a linear ohmic law $J_{\text {rev }} \sim V_{\text {rev }}$. The observed voltage dependence of the reverse biased current density reflects the current transport through an insulator layer [29]. Under a reverse bias the depletion region extends into the semiconductor and thus this part of the InSe substrate can be regarded as insulator. The extension of the depletion region leads to suppression of injection currents and emergence of the spacecharge limited currents, which determine the charge-carrier transport through the insulator layer [29].

Fig. 3 shows the frequency dependences of the $C-V$ characteristics of the graphite/n-InSe junctions measured at a low a.c.signal $(10 \mathrm{mV})$ under the reverse bias ranging from $0 \mathrm{~V}$ to $-3 \mathrm{~V}$. The observed linear dependences in the Mott-Schottky plot $C^{-2}(V)$ give an evidence of the uniform distribution of the uncompensated donors in the $n$-InSe substrate [27]. Thus, the graphite/ $n$-InSe structure under investigation can be considered as an abrupt electric junction.

The value of the built-in potential $V_{b i}$ can be established by extrapolating the lin-

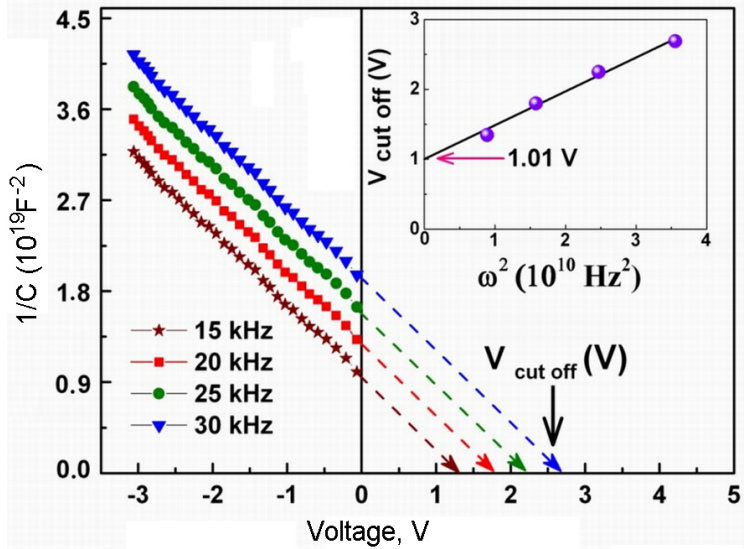

Fig. 3. Room temperature $C-V$ characteristics of the graphite $/ n$-InSe junction measured at different frequencies of a.c. signal. The inset shows the $V_{\text {cut off }}=f\left(\omega^{2}\right)$ plot.

ear dependence $C^{-2}(V)$ to the interception with the voltage axis (Fig. 3). The $C^{-2}(V)$ curves depend on a.c.frequency and are shifted to higher values of $C^{-2}(V)$ with increasing in frequency. The observed frequency dependence (Fig. 3) is associated with the influence of their series resistance $R_{s}=$ $3.5 \mathrm{k} \Omega$. To determine the real value of the built-in potential $V_{b i}$, it is necessary to approximate the received cut-off voltage to the zero frequency according to the equation [27]

$$
V_{c u t-o f f}=f\left(\omega^{2}\right)
$$

where $\omega=2 \pi f$ and $f$ is the linear frequency of the a.c.testing signal. The obtained dependence is shown in the inset of Fig. 3. As one can see, the approximated value $\left(V^{\prime}{ }_{b i}=\right.$ $1.01 \mathrm{~V})$ is overestimated in comparison to the band gap energy of InSe $\left(E_{g}=1.26 \mathrm{eV}\right)$. The significant difference between the built-in potential values determined from $J-V$ and $C-V$ characteristics may be associated with the effect of interfacial states. The only reliable parameter which can be obtained from the $C-V$ characteristics is the density of uncompensated donors $\mathrm{N}_{\mathrm{D}}$ in $n$-InSe substrate. This value can be calculated from the slope of the $C^{-2}(V)$ dependences using the equation [27]

$$
N_{D}=\frac{2 \Delta V}{q \varepsilon \varepsilon_{0} \Delta(S / C)^{2}},
$$

where $V$ is the applied voltage, $\varepsilon_{0}=$ $8.85 \cdot 10^{-14} \mathrm{~F} / \mathrm{cm}$ is the free space permittivity, $\varepsilon=7.6$ is the dielectric constant of InSe [30], $S$ is the area of the junction, and $C$ is the 


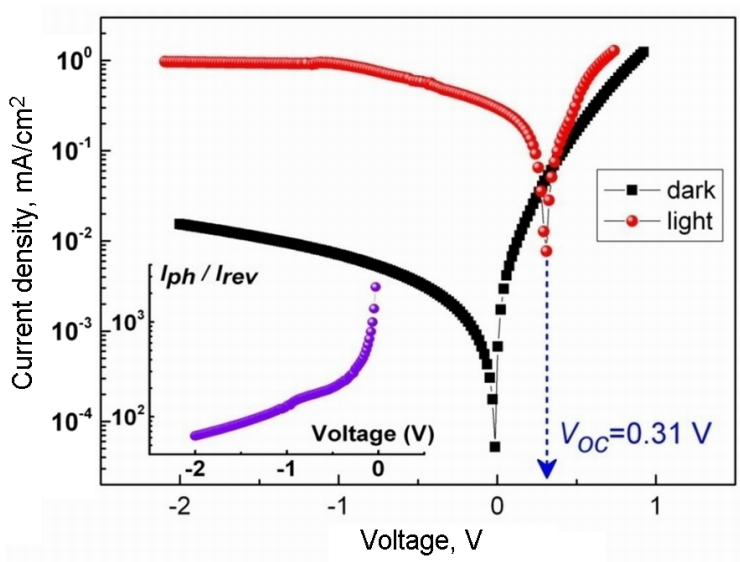

Fig. 4. Dark and light $J-V$ characteristics of the graphite $/ n$-InSe junctions. The inset shows the voltage dependence of the photocurrent to dark reverse current ratio.

junction capacitance. The calculated density of uncompensated donors $N_{D}=$ $4.77 \cdot 10^{14} \mathrm{~cm}^{-3}$ is in good agreement with the results of our Hall effect measurements.

\subsection{Photoelectric properties}

To verify the reproducibility of the used technique of fabrication of the graphite $/ n$-InSe devices, we prepared 30 samples. Their photoelectrical parameters slightly varied in different junctions but for all our samples, the deviations of the photoelectrical parameters from their average values did not exceed $10 \%$. The best samples produced an open-circuit voltage of $V_{o c}=0.31 \mathrm{~V}$ and a short-circuit current density of $J_{s c}=0.29 \mathrm{~mA} / \mathrm{cm}^{2}$ when exposed to $80 \mathrm{~mW} / \mathrm{cm}^{2}$ white light illumination. The filling factor $F F$ was calculated to be equal to 0.33 . The observed photosensitivity and photovoltaic action in the fabricated devices indicate the generation of photocarriers at the graphite/n-InSe interface.

Fig. 4 shows the room temperature $J-V$ characteristics of the graphite $/ n$-InSe junction measured in dark and under illumination with white light of a $80 \mathrm{~mW} / \mathrm{cm}^{2}$ intensity. One can see (Fig. 4) that the reverse bias current density under illumination is higher than that in the dark by about two or three order of magnitude. This is mainly associated with the generated electron-hole pairs contributing to the photocurrent because of the light absorption. We can also see that the photocurrent is voltage independent at high reverse bias $\left|V_{\text {rev }}\right|>1$ V. This indicates that the photogenerated carriers do not recombine within the space charge region or at the junction interface and are efficiently separated by the strong internal electric field. The inset in Fig. 4 shows a voltage dependent ratio of the photocurrent density to the dark reverse current density $J_{p h} / J_{r e v}$ suggesting that the graphite $/ n$-InSe junctions can be successfully applied as photodiodes with operating voltage up to $1.6 \mathrm{~V}$.

Fig. 5a shows the plot of the room temperature photocurrent quantum efficiency $\eta$ versus photon energy indicating a broadband spectral photosensitivity of the obtained graphite $/ n$-InSe junctions. The spectrum is characterized by the band width $\delta_{1 / 2}=0.96 \mathrm{eV}$ at its half-height. The abrupt long-wavelength edge of the $\eta$ spectrum is observed at the photon energies close to the InSe bandgap energy. This long-wavelength exponential increase of the $\eta=f(h v)$ dependence is associated with light absorption in InSe and is characterized by a high value of the slope $S \approx 50 \mathrm{eV}^{-1}$ derived from the following equation [27]:

$$
S=\Delta(\ln \eta) / \Delta h v,
$$

where $h v$ is the photon energy. The junctions are photosensitive in the spectral region from about $1.2 \mathrm{eV}$ to $2.95 \mathrm{eV}$, which demonstrates their potential as photodetectors for a wide range. Note that a well pronounced exciton peak was found in the photocurrent quantum efficiency spectrum at the photon energy of $E_{e x}=E_{g}-E_{b}=$ $1.249 \mathrm{eV}$ (Fig. 5a), where $E_{g}=1.264 \mathrm{eV}$ and $E_{b}=0.015 \mathrm{eV}$ are the direct-band gap energy and exciton binding energy in bulk InSe at $T=300 \mathrm{~K}$, respectively [4, 10, 31]. The presence of the exciton peak at room temperature indicates a high quality of the InSe substrate, as it is known that excitonic absorption is not observed in imperfect crystals [32].

The obtained results demonstrate that these devices can operate efficiently at room temperature in both photoconductive and photovoltaic modes and therefore they are promising candidates for the near-infrared and visible spectrum photodetectors. It should be noted that photodetectors based on InSe and GaSe crystals have been reported to exhibit very good radiation resistance to high-energy irradiations [23, 24, $26,33]$. In addition, graphite is well known to be highly resistant to all types of radioactivity. Therefore, it is expected that the 

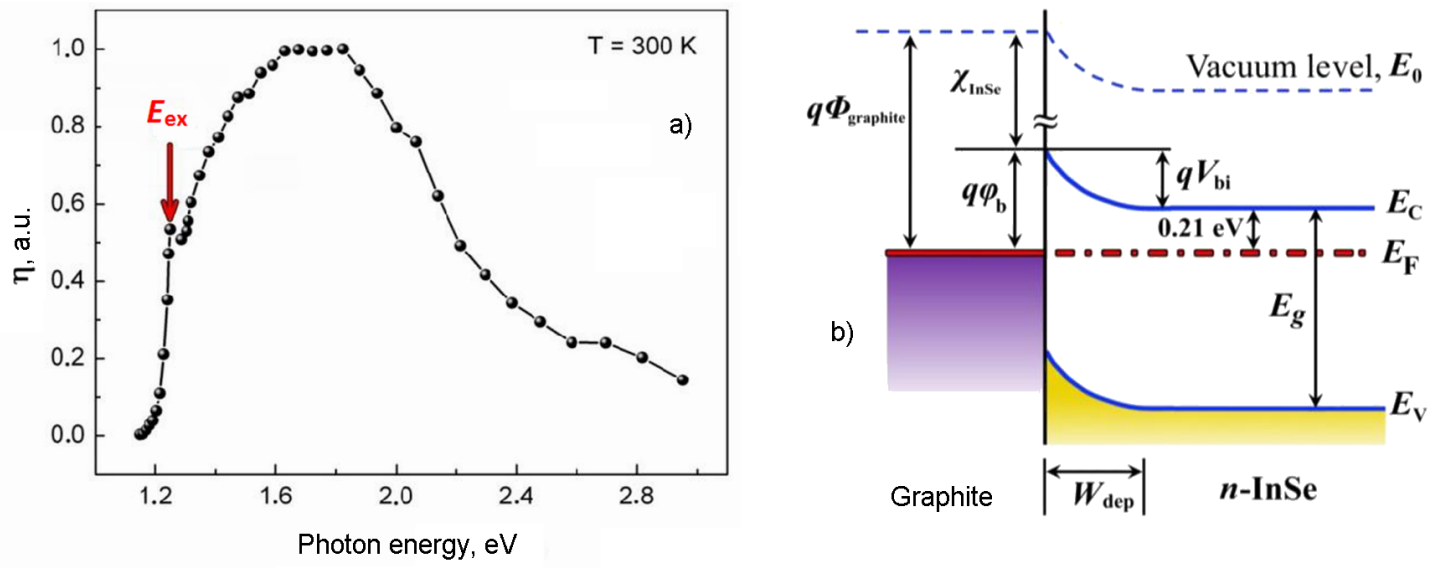

Fig. 5. a) Room temperature photocurrent quantum efficiency spectrum for the graphite/n-InSe junction. The arrow indicates the exciton peak energy position; b) the energy band diagram of the graphite/ $n$-InSe junction in thermal equilibrium.

graphite $/ n$-InSe junctions will provide high radiation resistance as well.

\subsection{Energy band diagram of the graphite/} $n$-InSe junction

Starting from the obtained experimental data, the energy band diagram of the graphite/ $n$-InSe Schottky-type junction can be built up. According to [34], the effective density of states $N_{C}$ of electrons in the conduction band of $n$-InSe is

$$
N_{C}=2\left(\frac{2 \pi m_{n} k T}{h^{2}}\right)^{3 / 2},
$$

where $m_{n}=0.15 m_{0}=\left[\left(m_{n}^{\perp C}\right)^{2} m_{n}^{\| C}\right]^{(1 / 3)}$ is the average effective mass of the electron masses parallel $\left(m_{n}^{\| C}=0.143 m_{0}\right)$ and perpendicular $\left(m_{n}^{\perp C}=0.156 m_{0}\right)$ to the $c$-axis [3] and $m_{0}$ is the electron mass in vacuum, and at $T=300 \mathrm{~K}$ gives the values $N_{C}=$ $2.1 \cdot 10^{18} \mathrm{~cm}^{-3}$. The position of Fermi energy level in $n$-InSe at $T=300 \mathrm{~K}$, when the dominating shallow donors are preferably ionized, was calculated using the following equation [36]:

$$
E_{C}-E_{F}=k T \ln \left(\frac{N_{C}}{N_{D}}\right),
$$

where $E_{C}$ and $E_{F}$ are the conduction band and Fermi energy, respectively, $N_{D}=$ $4.77 \cdot 10^{14} \mathrm{~cm}^{-3}$ is the density of uncompensated donors determined from the $C-V$ measurements. It was estimated that $E_{C}-$ $E_{F}=0.21 \mathrm{eV}$. The built-in voltage to be $V_{b i}$
$=0.28 \mathrm{~V}$ was calculated from the equation [27]

$$
q V_{b i}=q \varphi_{b}-\left(E_{C}-E_{F}\right)
$$

where the height of the Schottky barrier determined from the $J-V$ characteristic was found to be $\varphi_{b}=0.49 \mathrm{~V}$. For the abrupt junctions under investigation, the depletion-layer width $W_{d e p}$ can be calculated using the following equation [27]:

$$
W_{d e p}=\left(\frac{2 \varepsilon_{0} \varepsilon\left(V_{b i} \pm V\right)}{q N_{D}}\right)^{1 / 2},
$$

where $V$ is a voltage applied to the junction. The calculated depletion-layer width under thermal equilibrium conditions, i.e. at $V=$ $0 \mathrm{~V}$, is equal to $W_{d e p}=7 \cdot 0 \cdot 10^{-5} \mathrm{~cm}$.

The Schottky-Mott rule relating the Schottky barrier height to the metal work function and the semiconductor affinity can be used to calculate the graphite contact work function:

$$
\varphi_{b}=\Phi_{\text {graphite }}-\chi_{\operatorname{lnSe}}
$$

where $\chi_{\operatorname{lnSe}}=4.55 \mathrm{eV}$ [31] is the electron affinity of InSe. This obtained value of the graphite work function $\Phi_{\text {graphite }}$ is equal to $5.04 \mathrm{eV}$, which is in good agreement with the experimental data, ranging from 4.4 to $5.2 \mathrm{eV}$, reported in [17,35]. On the basis of the data above the energy band diagram of the investigated graphite/ $n$-InSe junction has the view shown in Fig. 5b. 


\section{Conclusions}

In summary, we demonstrated the formation of photosensitive Schottky-type graphite $/ n$-InSe junctions as a result of direct mechanical adhesion (strong van der Waals attraction) when a substrate-free thin dry drawn graphite film is transferred from water surface onto atomically smooth van der Waals surface (0001) of $n$-InSe crystal substrate. The applied technique is surprisingly well reproducible despite its technological simplicity.

We carried out a detailed investigation of electrical and photoelectrical properties of the fabricated junctions in dark and under illumination. The graphite $/ n$-InSe Schottky-type junctions exhibited well-pronounced diode-like behaviour with a rectification ratio $R R$ of about 200 at $0.9 \mathrm{~V}$. Using the Schottky-Mott relation we estimated the graphite contact work function to be equal to $5.04 \mathrm{eV}$, which is in good agreement with literature data. The unoptimized photosensitive junctions produced a maximum short circuit current density of $J_{s c}=$ $0.29 \mathrm{~mA} / \mathrm{cm}^{2}$, an open-circuit voltage of $V_{o c}$ $=0.31 \mathrm{~V}$ and filling factor of $F F=0.33$ under white light illumination of $80 \mathrm{~mW} / \mathrm{cm}^{2}$ intensity. The obtained graphite/n-InSe junctions exhibited relatively high sensitivity to light in the near infrared and visible spectral range, thus demonstrating technological potential of this pair for photodetector applications. They are promising due to graphite's mechanical stability and resistance to radioactive radiation, diffusion, high temperature, moisture, and most chemicals.

Our study may pave the way for further development of the new-emerging concept of pencil-on-semiconductor electronics. The obtained results represent a good starting point for fabrication and characterization of the next-generation photosensitive Schottky-type junctions "graphite/layered semiconductor" for optoelectronic, photovoltaic and nanoelectronics applications.

\section{References}

1. A.K.Geim, I.V.Grigorieva, Nature, 499, 419 (2013).

2. C.W.Lin, Z.Zhao, J.Kim, J.Huang, Sci.Rep., 4, 3812 (2014).

3. O.Madelung, Semiconductor: Data Handbook, 3rd ed., Springer-Verlag, Berlin (2004).

4. G.W.Mudd, S.A.Svatek, T.Ren et al., $A d v$. Mater., 25, 5714 (2013).

5. M.Hamer, E.Tovari, M.Zhu et al., Nano Lett., 18, 3950 (2018).

6. D.A.Bandurin, A.V.Tyurnina, G.L.Yu et al., Nature Nanotech., 12, 223 (2017).
7. J.F.Sanchez-Royo, G.Munoz-Matutano, M.BrotonsGisbert et al., Nano Res., 7, 1556 (2014).

8. G.W.Mudd, A.Patane, Z.R.Kudrynskyi, et al., Appl.Phys. Lett., 105, 221909 (2014).

9. A.I.Dmitriev, V.V.Vishnjak, G.V.Lashkarev et al., Phys. Solid State, 53, 622 (2011).

10. N.Balakrishnan, Z.R.Kudrynskyi, M.W.Fay et al., Adv. Opt. Mater., 2, 1064 (2014).

11. V.N.Katerinchuk, M.Z.Kovalyuk, Phys.Status Solidi A, 133, K45 (1992).

12. V.M.Katerynchuk, Z.R.Kudrynskyi, Z.D.Kovalyuk, J.Nano-Electron.Phys., 4, 02042 (2012).

13. A.N.Obraztsov, E.A.Obraztsova, A.V.Tyurnina, A.A.Zolotukhin, Carbon, 45, 2017 (2007).

14. T.Paulmier, J.M.Bell, P.M.Fredericks, Thin Solid Films, 515, 2926 (2007).

15. H.C.Semmelhack, R.Hohne, P.Esquinazi et al., Carbon, 44, 3064 (2006).

16. R.Yatskiv, V.V.Brus, M.Verde et al., Carbon, 77, 1011 (2014).

17. S.Tongay, T.Schumann, A.F.Hebard, Appl. Phys.Lett., 95, 222103 (2009).

18. V.V.Brus, P.D.Maryanchuk, Appl.Phys. Lett., 104, 173501 (2014).

19. V.V.Brus, P.D.Maryanchuk, Carbon, 78, 613 (2014).

20. G.Zheng, L.Hu, H.Wu, X.Xie, Y.Cui, Energy Environ.Sci., 4, 3368 (2011).

21. Y.Wang, H.Zhou, Energy Environ.Sci., 4, 1704 (2011).

22. K.Uosaki, M.Koinuma, J.Appl.Phys., 74, 1675 (1993).

23. Z.D.Kovalyuk, O.A.Politanska, V.G.Tkachenko et al., J. Nucl. Mater., 385, 489 (2009).

24. Z.D.Kovalyuk, O.A.Politanska, O.N.Sydor, V.T.Maslyuk, Semiconductors, 42, 1292 (2008).

25. P.I.Savitskii, Z.D.Kovalyuk, I.V.Mintyanskii, Inorg. Mater., 32, 361 (1996).

26. O.N.Sydor, O.A.Sydor, Z.D.Kovalyuk, V.I.Dubinko, Semiconductors, 48, 239 (2014).

27. S.M.Sze, K.K.Ng, Physics of Semiconductor Devices, John Wiley \& Sons, New Jersey (2007).

28. A.P.Bakhtinov, V.M.Vodopyanov, Z.R.Kudrynskyi et al., Phys. Status Solidi A, 211, 342 (2014).

29. M.A.Lampert, P.Mark, Current Injection in Solids, Academic Press, New York (1970).

30. D.Errandonea, A.Segura, V.Munoz, A.Chevy, Phys. Rev. B, 60, 15866 (1999).

31. O.Lang, A.Klein, C.Pettenkofer et al., J.Appl. Phys., 80, 3817 (1996).

32. B.Abay, H.S.Guder, H.Efeoglu, Y.K.Yogurtcu, J.Phys. .D: Appl.Phys., 32, 2942 (1999).

33. Z.D.Kovalyuk, V.M.Katerynchuk, I.V.Mintyanskii et al., Mater.Sci.Eng. B, 118, 147 (2005).

34. V.L.Bonch-Bruevich, S.G.Kalashnikov, Physics of Semiconductors, Nauka, Moscow (1990) [in Russian].

35. R.Yatskiv, J.Grym, Appl. Phys. Lett., 101, 162106 (2012). 